\title{
Prediction of phase, hardness and density of high entropy alloys based on their electronic structure and average radius
}

M. Calvo-Dahlborg ${ }^{1,2, *}$, S. Mehraban ${ }^{1}$, N.P. Lavery ${ }^{1}$, S.G.R. Brown ${ }^{1}$, J. Cornide ${ }^{2,3}$, J. Cullen ${ }^{1}$, J. Cieslak ${ }^{4}$, Z. Leong ${ }^{5}$, R. Goodall ${ }^{5}$, U. Dahlborg ${ }^{1,2}$

${ }^{1}$ Future Manufacturing Research Institute, College of Engineering, Swansea University, Bay Campus, Fabian Way, Swansea SA1 8EN, United Kingdom.

m.calvo-dahlborg@ swansea.ac.uk, u.dahlborg@swansea.ac.uk, s.mehraban@swansea.ac.uk, n.p.lavery@swansea.ac.uk, s.g.r.brown@swansea.ac.uk, J.C.T.Cullen@Swansea.ac.uk.

${ }^{2}$ Normandie Univ., UNIROUEN, INSA Rouen, CNRS, GPM, 76000 Rouen, France monique.calvo-dahlborg@univ-rouen.fr, ulf.dahlborg@univ-rouen.fr.

${ }^{3}$ Now at Department of Materials Science and Engineering, IAAB, Universidad Carlos III de Madrid. Avda. Universidad 30, 28911 Leganés, Spain. jcornide@ing.uc3m.es

${ }^{4}$ AGH University of Science and Technology, Faculty of Physics and Applied Computer Science, Al. Mickiewicza 30, 30-059 Cracow, Poland. Jakub.Cieslak@ fis.agh.edu.pl

${ }^{5}$ Department of Materials Science and Engineering, Sheffield University, Sir Robert Hadfield Building, Mappin Street, Sheffield, S1 3JD, UK. zhaoyuan@sheffield.ac.uk, r.goodall@sheffield.ac.uk

* Corresponding author: monique.calvo-dahlborg@univ-rouen.fr.

\section{Abstract:}

According to a recent Hume-Rothery approach, the electron concentration, e/a, and the average radius can be used to identify the domain of stability of HEAs and to estimate the phases that may occur in the alloy. The present study investigates the influence of the electronic structure and the average radius on the hardness for a series of HEA alloys. The alloys investigated in this work all contained $\mathrm{Co}, \mathrm{Fe}$ and $\mathrm{Ni}$ as base elements. To this base system one or more elements were added, including $\mathrm{Al}, \mathrm{Cr}, \mathrm{Cu}, \mathrm{Sn}, \mathrm{Pd}, \mathrm{Ru}, \mathrm{Ti}$, and $\mathrm{V}$ in different proportions. For comparison, data on phases identified and hardness have been taken from a wide range of bibliography for other types of alloys in the systems Co-Cr-Fe-Cu-A-B-C-D-E-F, with A, B, C, D, E, F = Al, Ti, V, Nb, Cu, Mo, Mn, B, Si, Y, Sc, Ru, Re, Gd, Dy, Ho, Lu, Tb, Er, Tm, La, W, Ta, Hf, Zr. In order to predict the occurrence of mainly fcc, bcc and hcp phases, the average atomic radius is preferable over to the average radius for a 12 nearest atoms neighbourhood. Based on this [e/a; radius] system, it is shown that the hardness of the HEA composition can be predicted. By using this classification, it is possible to determine compositions of HEA alloys with adequate range of hardness, density and phases present. The consequences of such 
predictions when modelling the structure and mechanical behaviour of HEAs is fundamental for their application.

Keywords: High Entropy Alloys, design, phases, hardness, density

\section{Introduction}

In 2004 the first reference was made of "high entropy alloys" (HEA) to designate alloys consisting of five or more principal elements in equi- or near-equimolar amounts (5 to 35 at\%), having simple crystalline structures and extraordinary properties [1]. The same year another publication reported the structure and microstructure of equiatomic multicomponent alloys from 5 to 20 elements [2]. The notion of high entropy refers to their high entropy of mixing. Since 2004 these alloys have been intensely investigated with respect to phase composition, microstructure, as well as thermal, magnetic and mechanical properties [3-11]. It is now well established that HEAs can be single-structured $[12,13]$ but are not, or are almost never, singlephased [14]. The identified structures belong in most cases to the face centred cubic (fcc-type), the body centred cubic (bcc-type) and hexagonal close packed (hcp-type) families of structures. It should be noted, though, that the identification of crystalline structures present in a manyphase alloy is a very complicated matter and successful characterization depends on the resolution of the experimental technique used. Since their discovery, the determination of the phase stability of HEAs after solidification has been a significant issue in many investigations. Phase changes due to external fields (temperature, pressure, etc) have been found to have a profound influence on the microstructure and, thus, the mechanical and magnetic properties. For this purpose, a combination of parameters relevant in this context have been considered for their synthesis, including aspects of phase formation, microstructure and phase stability, strengthening mechanisms, and high temperature properties, as well as the density and cost [1521]. 
In the course of these investigations [1-21] it was shown that due to a unique combination of crystalline structures and microstructures several HEAs can potentially outcompete conventional alloys today in use in specific technological applications. Thus, a new approach to metallurgy has emerged in that all elements have to be considered on an equal footing during the solidification process. This is different to traditional alloys which usually consist of a leading ternary or binary system, such as for example Ti-Al, while the other elements can be considered as minor additions. Thus, the designation, "multi-principal element alloys", is also used for high entropy alloys.

The design of alloys that contain phases with specific crystalline structures is of utmost importance in order to predict physical properties. An alloy containing fcc, bcc or hcp phases will have a very different mechanical behaviour and response to stress. Thus, many works have reported the influence of compositions and phases on mechanical properties, especially hardness [22-69].

The present work focusses on the use of a recent classification $[31,70]$ for predicting phases in order to anticipate the hardness of HEAs. All investigated alloys contain Co, Fe and $\mathrm{Ni}$ as base components (abbreviated to $\mathrm{CFN}$ below). When $\mathrm{Cr}$ is also present the abbreviation CCFN is used.

\section{Material and methods}

The alloys investigated in this work all contained $\mathrm{Co}, \mathrm{Fe}$ and $\mathrm{Ni}$ as base elements. To this base system one or more elements were added, including $\mathrm{Al}, \mathrm{Cr}, \mathrm{Cu}, \mathrm{Sn}, \mathrm{Pd}, \mathrm{Ru}, \mathrm{Ti}$, and V in different proportions. All alloys were prepared by arc melting of pure elements, with purities higher than 99.9 wt.\% [14,71]. The alloys were re-melted several times in order to obtain homogeneity and to minimize oxide impurities.

The crystalline structure of the phases that were found in these alloys as well as the corresponding lattice constants were determined by high resolution diffraction techniques 
[14,72-75]. All diffraction studies were performed on as-cast materials. All diffraction studies were performed on as-cast materials [76] and the crystalline structure of the phases present in the alloys were determined by a refinement procedure using the DICVOL computer code [77]. All measurements were performed at ambient temperature.

Microstructures of most of the alloys presented in the manuscript have been published in other papers by the authors: CoCrFeNi, CoCrFeNiPd, CoCrFeNiRu and CoCrFeNiSn in reference [74,75]. $\mathrm{CoCr}_{\mathrm{x}} \mathrm{FeNiAl}_{\mathrm{y}}$ in reference [71] and $\mathrm{CoCrFeNiPd}$ in reference [72,74,75].

Microhardness measurements were performed on a Wilson VH3300 Automatic Vickers/Knoop Hardness Testers. Since each specimen was relatively thin, samples were mounted in phenolic resin and then placed into the sample carrier to ensure no movement of the sample during the hardness indentation. A load setting of Vickers HV1 was used with a dwell time of 10 seconds. Each indent was measured at 20x magnification and matrix array of $4 \times 4$ indents with a $0.3 \mathrm{~mm}$ spacing were made over the surface of the sample. The mean hardness value was then taken and used in this paper.

For comparison, data on phases identified and hardness have been taken from a wide range of bibliography for other types of alloys [1,3,18,23,26,28,32-69] in the systems Co-CrFe-Cu-A-B-C-D-E-F, with composition ranging from 0 to 35 at $\%$ and $\mathrm{A}, \mathrm{B}, \mathrm{C}, \mathrm{D}, \mathrm{E}, \mathrm{F}=\mathrm{Al}$, Ti, V, Nb, Cu, Mo, Mn, B, Si, Y, Sc, Ru, Re, Gd, Dy, Ho, Lu, Tb, Er, Tm, La, W, Ta, Hf, Zr. The exact compositions, reported phases and hardness can be found in these studies. Results are reported at the end of this work for some designed alloys in order to present the design strategy. For confidentiality reasons the compositions of these alloys cannot be detailed for the moment.

\section{Results and discussion}

\subsection{A summary of the proposed classification system}


Recently a classification of HEAs with respect to the phases present was proposed using the average value of the electron concentration or number of itinerant electrons per atom (e/a) in the alloy and the average radius calculated for a 12 -atoms neighbourhood $[31,70]$.

The importance of the number of itinerant electrons per atom in understanding and predicting the phases in solid solutions was stressed as early as 1966 [78]. In [79] the use of e/a is discussed by Massalski for the determination of Hume-Rothery phases as opposed to an approach using the total number of valence electrons per atom (VEC) (which includes the d electrons). By applying this approach for HEAs as solid solutions a classification and design methodology was proposed [31]. From the variation of the average magnetic moment per atom and the hardness as a function of e/a and the 12 atoms radius, three Domains were identified [31,70]: All alloys belonging to a specific Domain have been reported to have the type of structure in the as-cast state as predicted by the classification scheme: Thus, in Domain I (e/a $<1.53$ ) alloys with fcc or hcp structures are found while the alloys in Domain III (e/a >1.88) contain structures of bcc type. The alloys in Domain II $(1.53<\mathrm{e} / \mathrm{a}<1.88)$ form both fcc and bcc structures as well as other intermetallics. It was also concluded that when the composition of a HEA includes nickel the Ni electronic structure should be considered as being [Ar] $3 \mathrm{~d} 94 \mathrm{~s} 1$ instead of the usually used [Ar] 3d8 4s2 [70].

The atomic radii were taken from Teatum [80] as these are probably the most useful when analysing diffraction data. They are reported for a coordination number 12 atomic structure and were obtained from considering observed atomic distances in face-centred cubic and hexagonal close-packed structures. The first property used for classification of HEAs was the magnetization at saturation $[31,70]$. The influence of different heat treatments on the stability of HEA has been reported to depend on its location within the three identified Domains [21].

\subsection{Vickers hardness as a function of the crystallographic structure of as-cast alloys}


For the use of HEAs in any industrial application the knowledge of the phases present is crucial as it will determine their mechanical behaviour. Even though hardness is silt only a surface property of a sample it was used in order to investigate the efficiency of the above classification. Furthermore, hardness can give a strong indication for surface properties of an alloy for further applications. Fig. 1 presents the measured Vickers hardness as a function of the calculated e/a for the investigated alloys. The vertical bars separate the three Domains, I, II and III of the classification system described above [31,70].

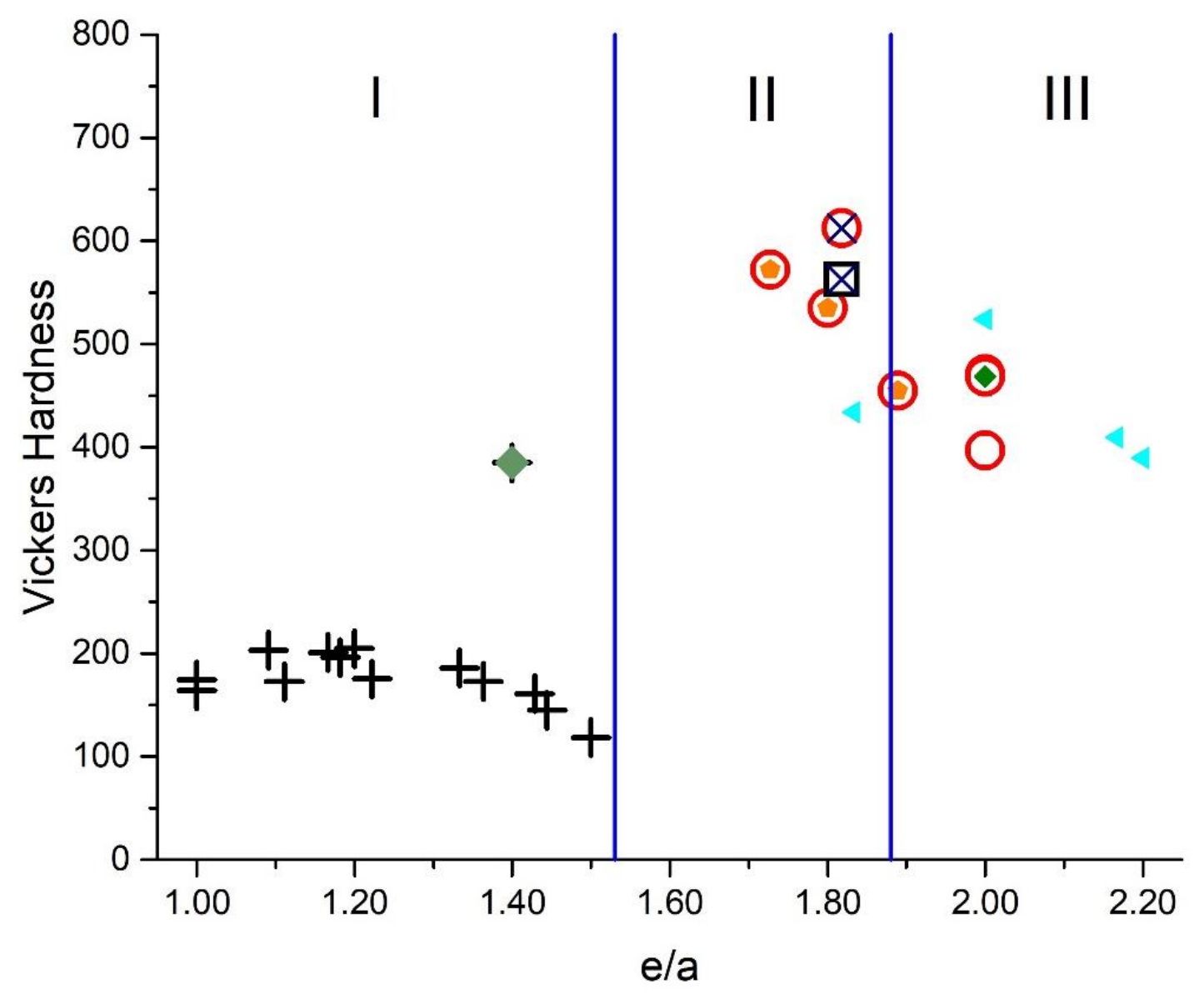

Fig. 1: Vickers hardness, as a function of e/a for the investigated alloys in as cast conditions. The symbols indicate the types of phases identified by diffraction: + fcc, $\circ$ bcc, $\bullet$ hcp, $\triangle \mathrm{B} 2$, 
fcc+bcc, $\times$ L21, $>$ no diffraction data available. The vertical bars define the domains I, II and III.

The following can be observed from Fig. 1:

- Domain I contains alloys with fcc $(+)$ and hcp $(\diamond)$ structure. Domain III contains alloys with bcc ( $\odot$ ) type of structure while Domain II contains alloys with different types of structure.

- $\quad$ Alloys with hcp $(\diamond)$ structure can be found in both Domains I and III.

- Alloys with fcc structure in Domain I have low hardness, almost independent of e/a, whereas alloys with hcp structure or in Domain III have moderate values of hardness. Alloys in Domain II have a rather large range of hardness values.

It was concluded in [31] that the electronic structure e/a alone was not enough to produce a suitable classification but that the simple combination of e/a and $r$ was necessary to give an accurate first estimation of the phases present. Applying a solid solution first approximation, the average radius $\mathrm{r}_{\text {Teatum }}$ for the alloys has been calculated from their atomic compositions as a linear combination of the radius of the individual constituting elements. Providing error bars for all of the calculated data (average radius, e/a) is acknowledged as challenging referring as it does to commonly used databases of physics, such as the radius for bcc, fcc and hep structure [80] and the number of different electrons per atom. Fig. 2 presents the variation of the measured Vickers hardness as a function of the 12 neighbours radius as reported by Teatum [80] for the investigated alloys. The two ranges of hardness values are clearly separated. 


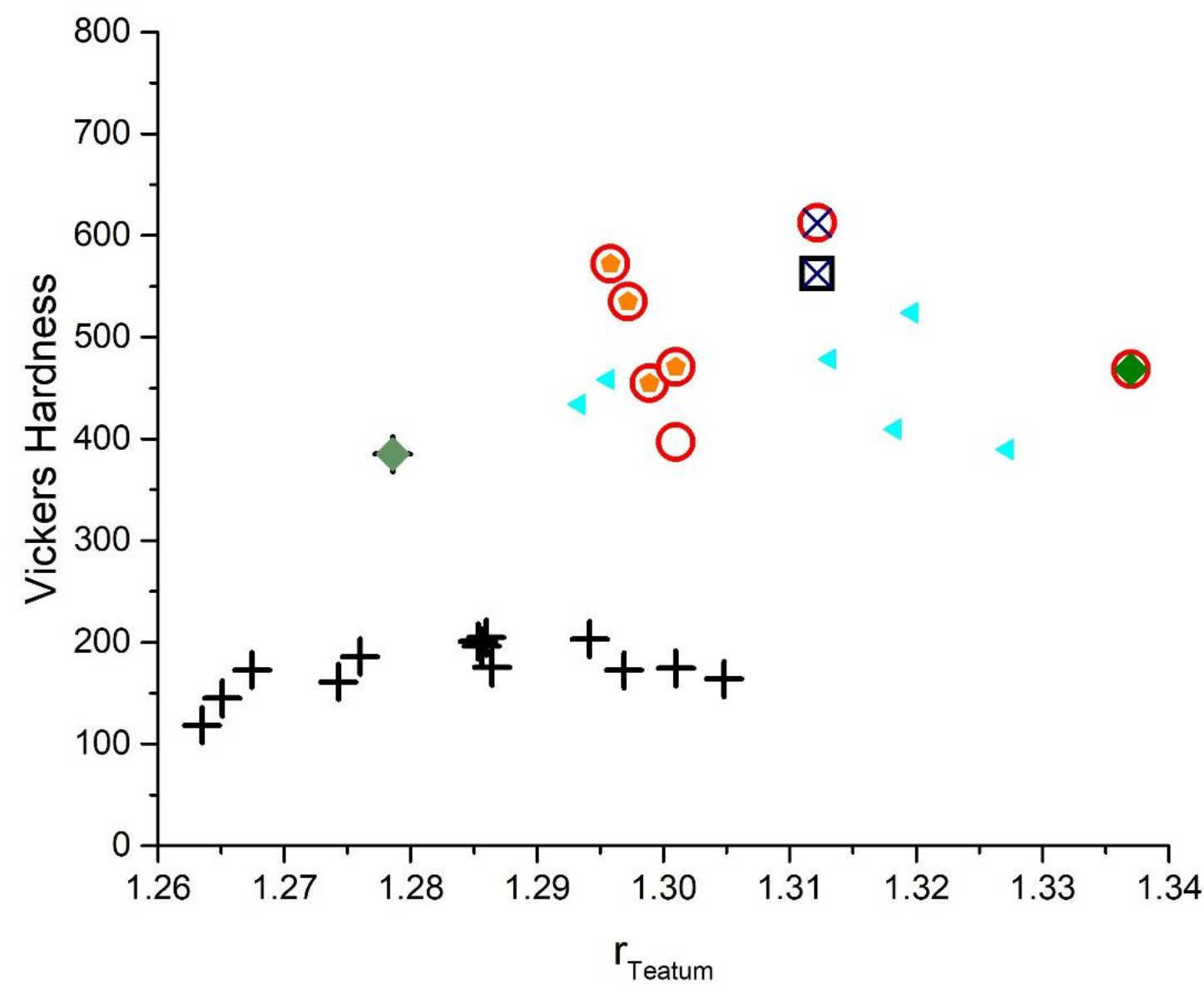

Fig. 2: Vickers hardness, as a function of the average calculated Teatum [80] radius for the investigated alloys in as cast conditions. The symbols indicate the types of phases identified by diffraction: + fcc, $\circ$ bcc, $\diamond$ hcp, $\triangle \mathrm{B} 2, \square$ fcc+bcc, $\times$ L21, $<$ no diffraction data available.

\subsection{Alloys with hep structure}

Alloys with fcc type and bcc type structures are very distinct in the hardness classification of Fig. 1. Alloys with fec structure are located in Domain I and alloys with bcc structure predominantly in Domain III. However, a noticeable feature of Fig1 and of the classification using the Teatum [80] radii [e/a, $\mathrm{r}_{\text {Teatum] }}$ (Fig. 2) is that hcp alloys are present in both Domain I and III. Several HEAs alloys have been found to contain hcp structure $[3,34,61,62,64,65,68,74]$.

As demonstrated in [31,70] for a complete classification to aid efficient alloy design, the combined influence of e/a and the radius on the phases present should be considered. 
Accordingly, Fig3 presents e/a as a function of the Teatum average radius [80] for all investigated alloys.

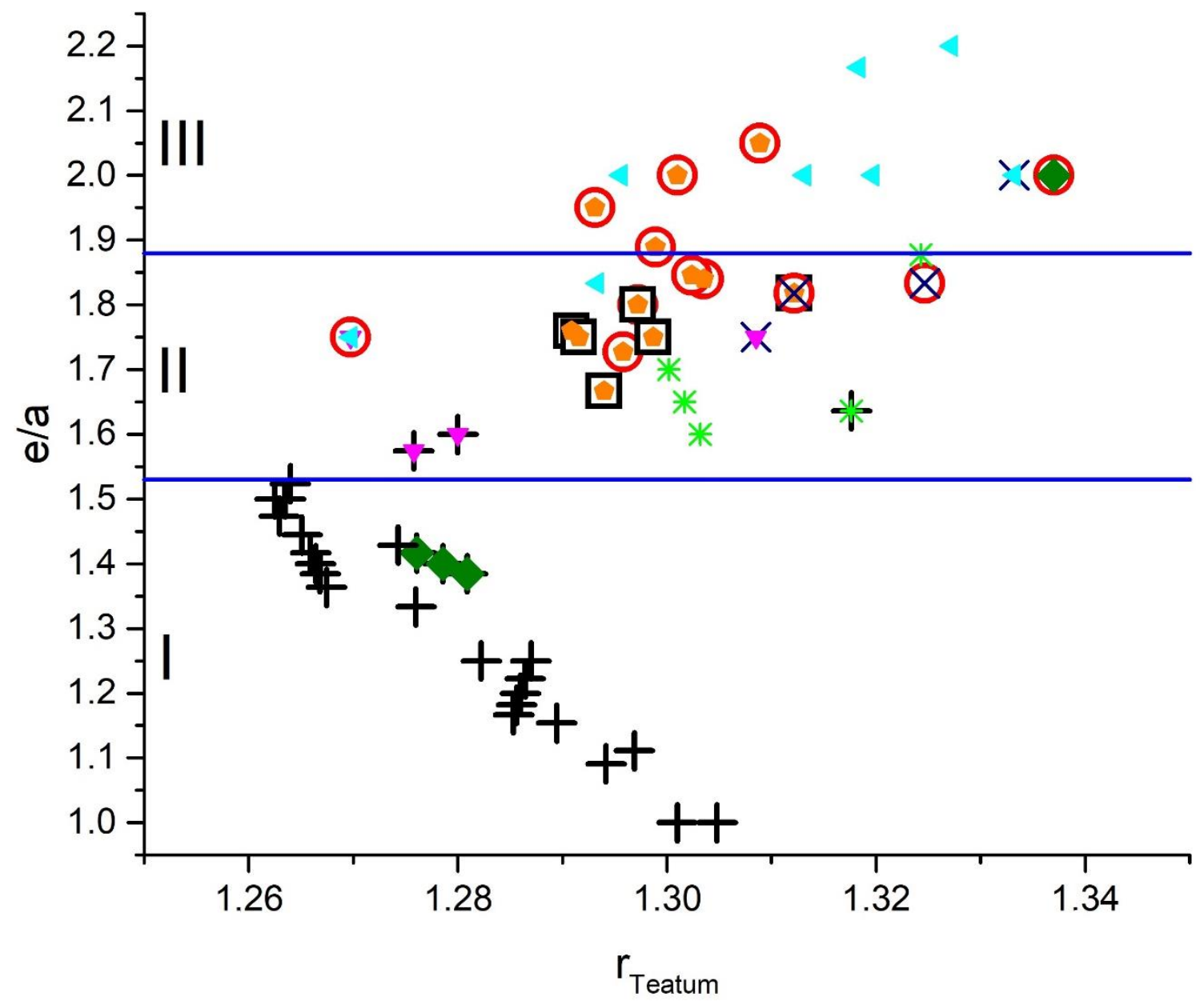

Fig. 3: e/a, as a function of $\mathbf{r}_{\text {Teatum }}$ for the investigated alloys in as cast conditions. The symbols indicate the types of phases identified by diffraction: + fcc, $\circ$ bcc, $\diamond$ hcp, $\triangle \mathrm{B} 2, \square$ fcc+bcc, $\times$ L $21, \nabla$ intermetallic or sigma phases, $*$ mixed phases, $\varangle$ no diffraction data available. The horizontal bars define the domains I, II and III.

From observation of Fig. 3 one can see that hcp is present in all three Domains. Thus, the present classification in terms of e/a and the 12 atoms neighbourhood average radius, $\mathrm{r}_{\text {Teatum }}$, is not satisfactory for the case of HEAs alloys containing hcp structure, especially in the case of hardness, i.e. for mechanical behaviour. 
As pointed out in [81] the exact "atomic diameter" of an element is always difficult to define. The atomic distances used in the Hume-Rothery approach are defined [82] as the closest distances of approach of atoms in the crystals of the elements. The radii given in [80] seemed in a first approximation to be the most useful for discussing metallic alloys as they are reported for a coordination number of 12 . They were obtained from the observed interatomic distances in fcc, hcp and bcc structures but for details of the calculation we refer to the original publication [80]. The Teatum radii have thus been used in the identification of phases from diffraction data because of this particular isotropic aspect. However, this average diameter may not necessarily be transferable to all alloys because the 'radius' of an atom is affected by the coordination number, i.e. its environment.

In the specific case of hardness, and of mechanical behaviour in general, it is very important to be able to clearly differentiate fcc, bcc but also hcp. The difference between the three structures is based on the packing of the atomic planes. Consequently, the average experimental atomic radius, $\mathrm{r}_{\text {Atomic}}$, of the alloy has been considered. The results for the same compositions as in Fig. 3 are presented in Fig. 4. 


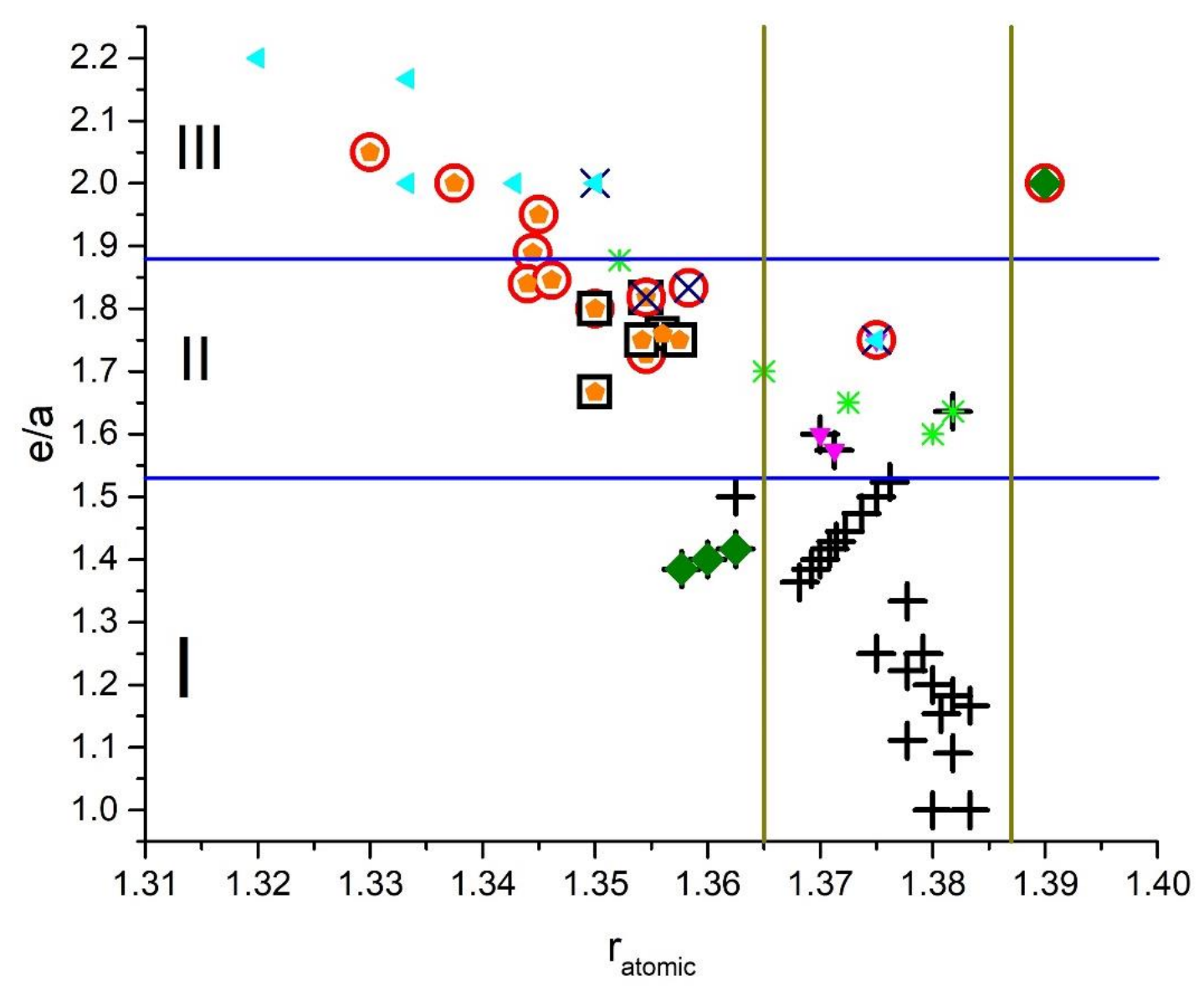

Fig. 4: e/a, as a function of atomic radius, $\mathrm{r}_{\text {Atomic }}$, for the investigated alloys in as cast conditions. The symbols indicate the types of phases identified by diffraction: $+\mathrm{fcc}, \circ \mathrm{bcc}, \bullet \mathrm{hcp}, \triangle \mathrm{B} 2$, fcc+bcc, $\times$ L21, $\nabla$ intermetallic or sigma phases, $*$ mixed phases, $\varangle$ no diffraction data available. The horizontal bars define the domains I, II and III. The vertical bars determine radius domains

From Fig.4, it can be concluded the following:

- The combined influence of e/a and the atomic radius clearly segregate alloys with fcc, bcc and hep types of structure.

- $\quad$ The three e/a Domains as identified in $[31,70]$ are still the following:

Domain I: fcc type, e/a $<1.53$

Domain III: bcc type, e/a > 1.88

Domain II: mixed phases (Sigma, intermetallics, etc), $1.53<\mathrm{e} / \mathrm{a}<1.88$. 
- Hcp structures seems now to exist only in two subregions. Thus, the following Domains might in this case be added for the occurrence of hcp phases:

$\mathrm{r}<1.365$ in Domain I

r> 1.387 in Domain III.

For elucidation, the correlation between e/a and $r_{\text {Atomic }}$ including HEAs from the bibliography results from the bibliography $[1,3,18,23,26,28,32-69]$ are presented in Fig. 5.

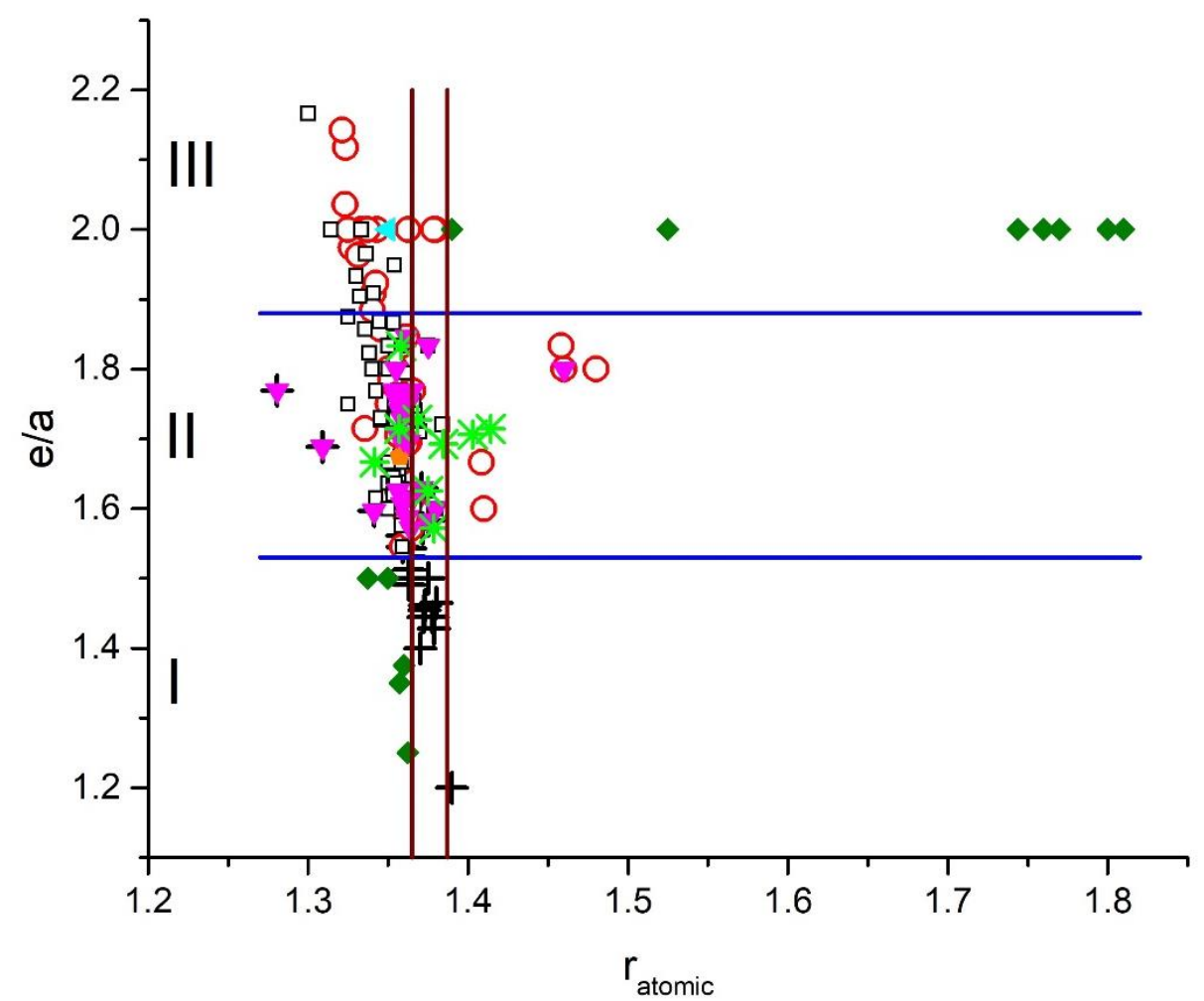




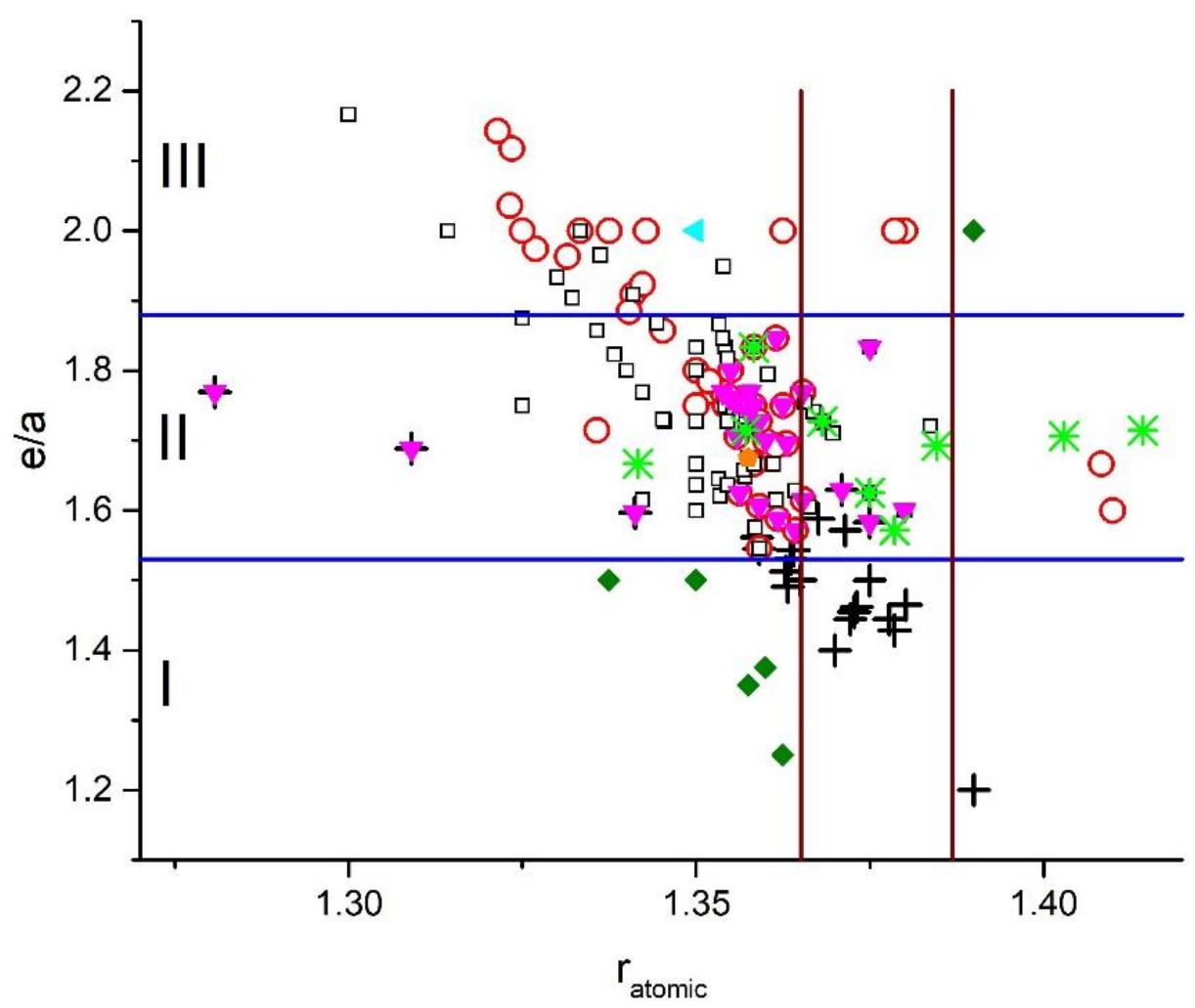

Fig. 5: e/a, as a function of atomic radius, $\mathrm{r}_{\text {Atomic }}$, for as cast bibliography alloys. The symbols indicate the types of phases identified by diffraction: + fcc, $\circ$ bcc, $\diamond$ hcp, $\triangle \mathrm{B} 2, \square$ fcc+bcc, $\times$ L21, $\nabla$ intermetallic or sigma phases, $*$ mixed phases, $<$ no diffraction data available. The horizontal bars define the domains I, II and III and the vertical bars the identified radius domains. a) The whole range of radius. b) A zoom to easy comparison with Fig. 4.

From the observation of Fig. 5 it can be seen, as in Fig. 4, that the use of the atomic radius, $r_{\text {Atomic }}$, is to be preferred to $\mathrm{r}_{\text {Teatum }}$ for the location of hcp structure. The horizontal bars define the domains I, II and III and the vertical bars the identified radius domains.

\subsection{Variation of alloy hardness and density within the [e/a, atomic radius] classification}

For convenience, the Vickers hardness data presented in Figs. 1 and 2 have been decomposed into three levels: below 300, between 300 and 450 and above 450. The results are presented in Fig. 6 in the framework of the [e/a; atomic radius] classification of Fig. 4. The horizontal bars 
represent the three Domains of e/a and the vertical bars the radius locations identified in Fig. 4 for hep alloys.

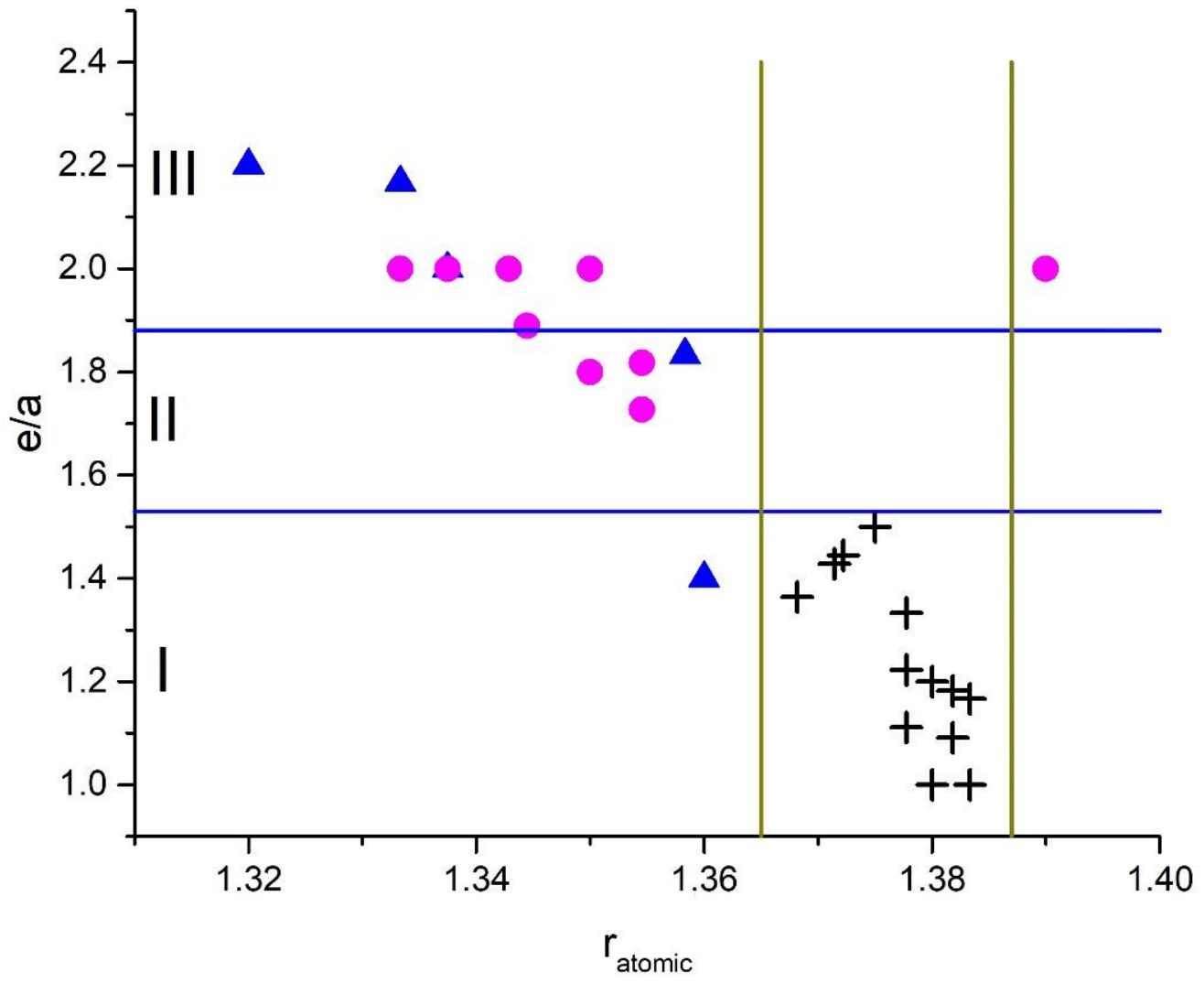




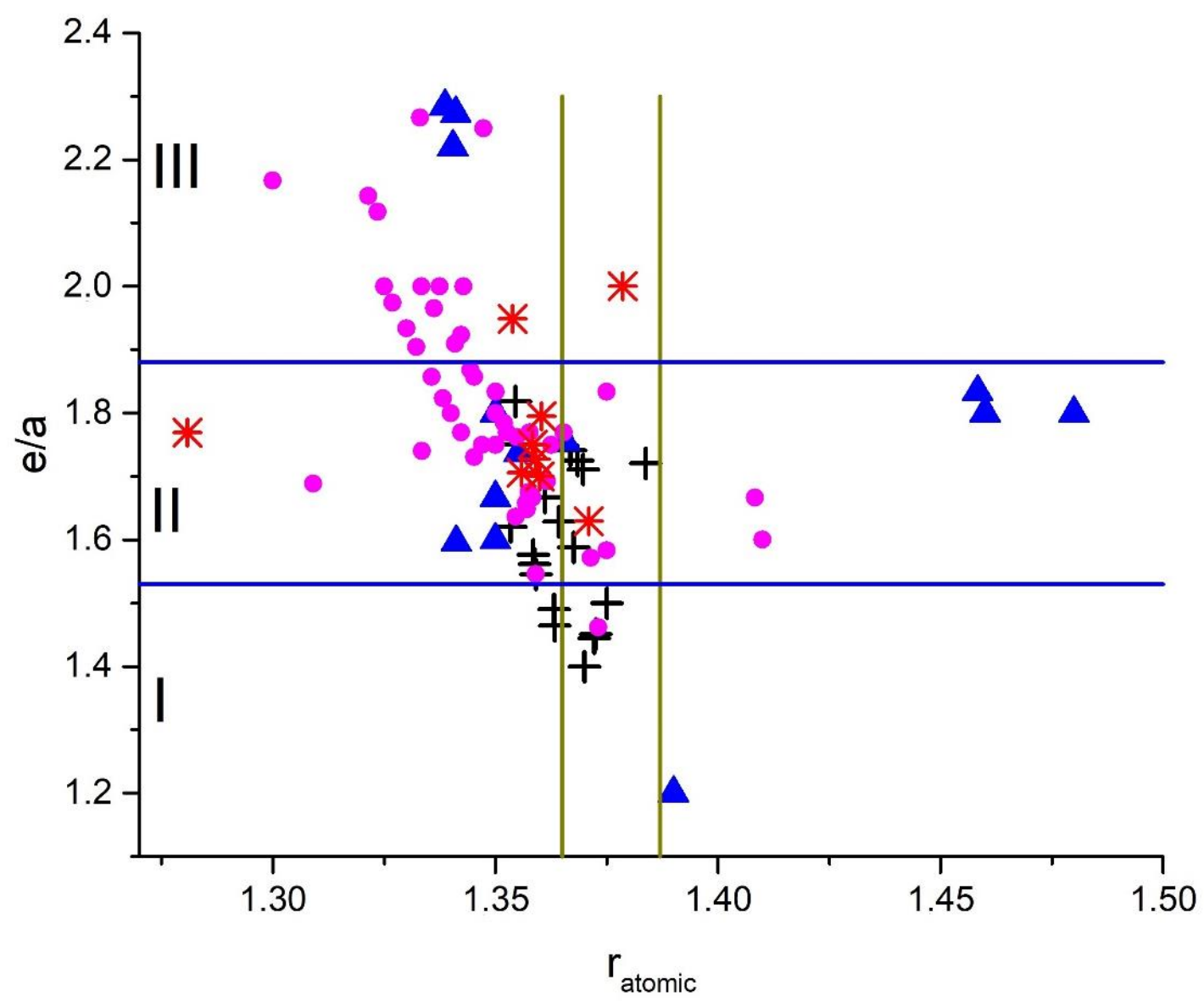

Fig. 6: e/a, as a function of atomic radius, $\mathrm{r}_{\text {Atomic, }}$ a) for the investigated alloys in as cast conditions, b) for as cast bibliography alloys. The symbols indicate the types of phases identified by diffraction: $+\mathrm{HV}<300,-300<\mathrm{HV}<450, \Delta \quad 450<\mathrm{HV}<700$, $* \mathrm{HV}>700$. The horizontal bars define the domains I, II and III and the vertical bars the radius domains identified in Fig. 4.

The separation of hardness values into different domains is clearly seen in Fig. 6a for the investigated alloys and confirmed by the comparison with the data found in bibliography and presented Fig.6b. The alloys located in Domain I, with fcc structure, have low hardness values while alloys in Domain III present hardness values above 300. 
For all investigated alloys the average density was calculated from textbook data of the constituent elements and their atomic percent. Fig. 7 presents the calculated density for the investigated alloys as a function of e/a, e.g. the same alloys as in Fig. 4. The vertical bars define the domains I, II and III.

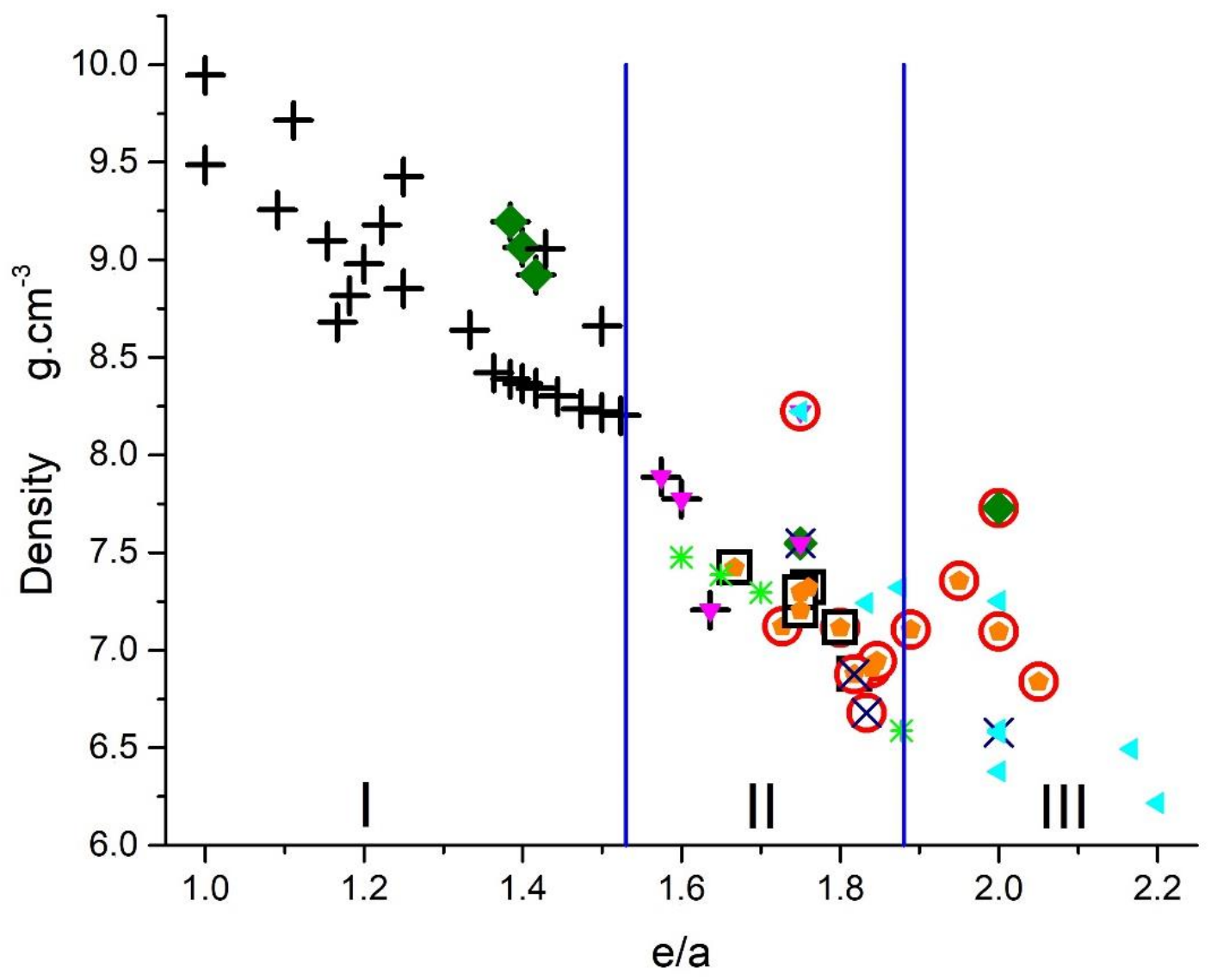

Fig. 7: Calculated density, as a function of e/a for the investigated alloys in as cast conditions. The symbols indicate the types of phases identified by diffraction: + fcc, $\circ$ bcc, $\bullet$ hcp, $\triangle \mathrm{B} 2$, $\square$ fcc+bcc, $\times$ L21,,$\nabla$ intermetallic or sigma phases, $*$ mixed phases, $\angle$ no diffraction data available. The vertical bars define the domains I, II and III.

On Fig. 7 it can be seen that the density variation with the electronic structure follows the same three Domains of phases as in $[31,70]$. 
It can thus be concluded that from the results presented in Fig. 6 and Fig. 7, and from the existence of domains as identified earlier and in Fig. 4, it should possible by using the above classification scheme [e/a; $\left.\mathrm{r}_{\text {Atomic }}\right]$ to design alloys with specific properties. This is demonstrated in the following section.

3.5 Design of alloys with specific phases composition, density and hardness within the [e/a, atomic radius] framework

Using the conclusions of Fig. 6 representing the different domains of hardness within the [e/a; radius] framework, as well as Fig. 4 and Fig. 7, compositions of HEAs alloys have been designed for specific phases, hardness values and density. The requested alloys were of two kinds:

1) HEA alloys with specific elements, bcc type of phases, Vickers hardness higher than 300 , density around 6 g.cm ${ }^{-3}$.

2) HEA alloys with specific elements, fcc type of phases, Vickers hardness lower than 300, density higher than 7 g. $\mathrm{cm}^{-3}$.

Fig. 8, a, b and c present the obtained results as compared with the prediction. In both Figs. $8 \mathrm{a}$ and $\mathrm{b}$ the variation of $\mathrm{e} / \mathrm{a}$ as a function of the atomic radius is presented for the designed alloys. In Fig. 8a the symbols indicate the phases present and in fig. $8 \mathrm{~b}$ the range of the measured hardness. 


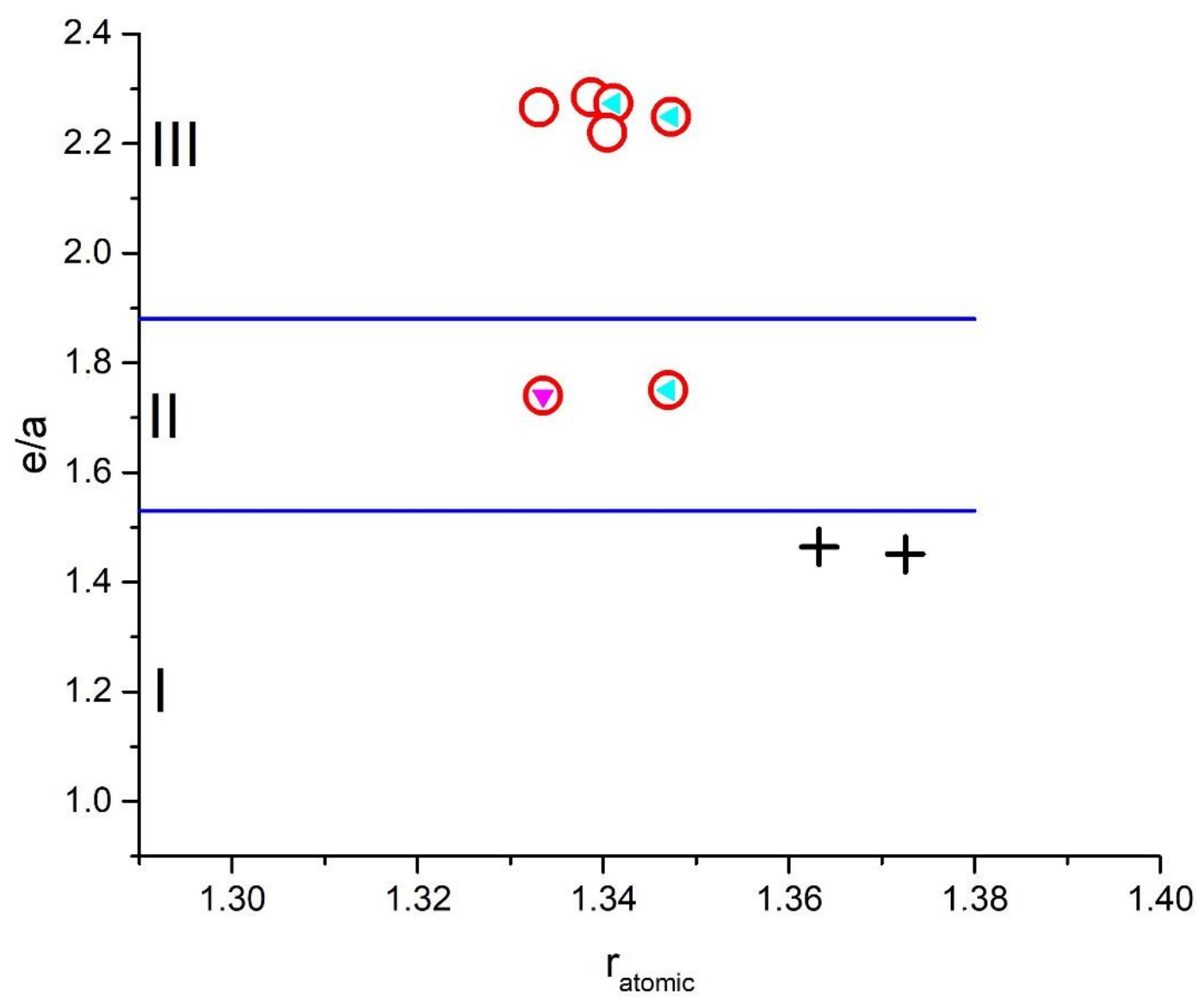

Fig. 8a: e/a as a function of atomic radius for the designed alloys. The symbols indicate the types of phases identified by diffraction: $+\mathrm{fcc}, \circ \mathrm{bcc}, \nabla$ intermetallic or sigma phases $\langle$ no diffraction available. The horizontal bars define the domains I, II and III. 


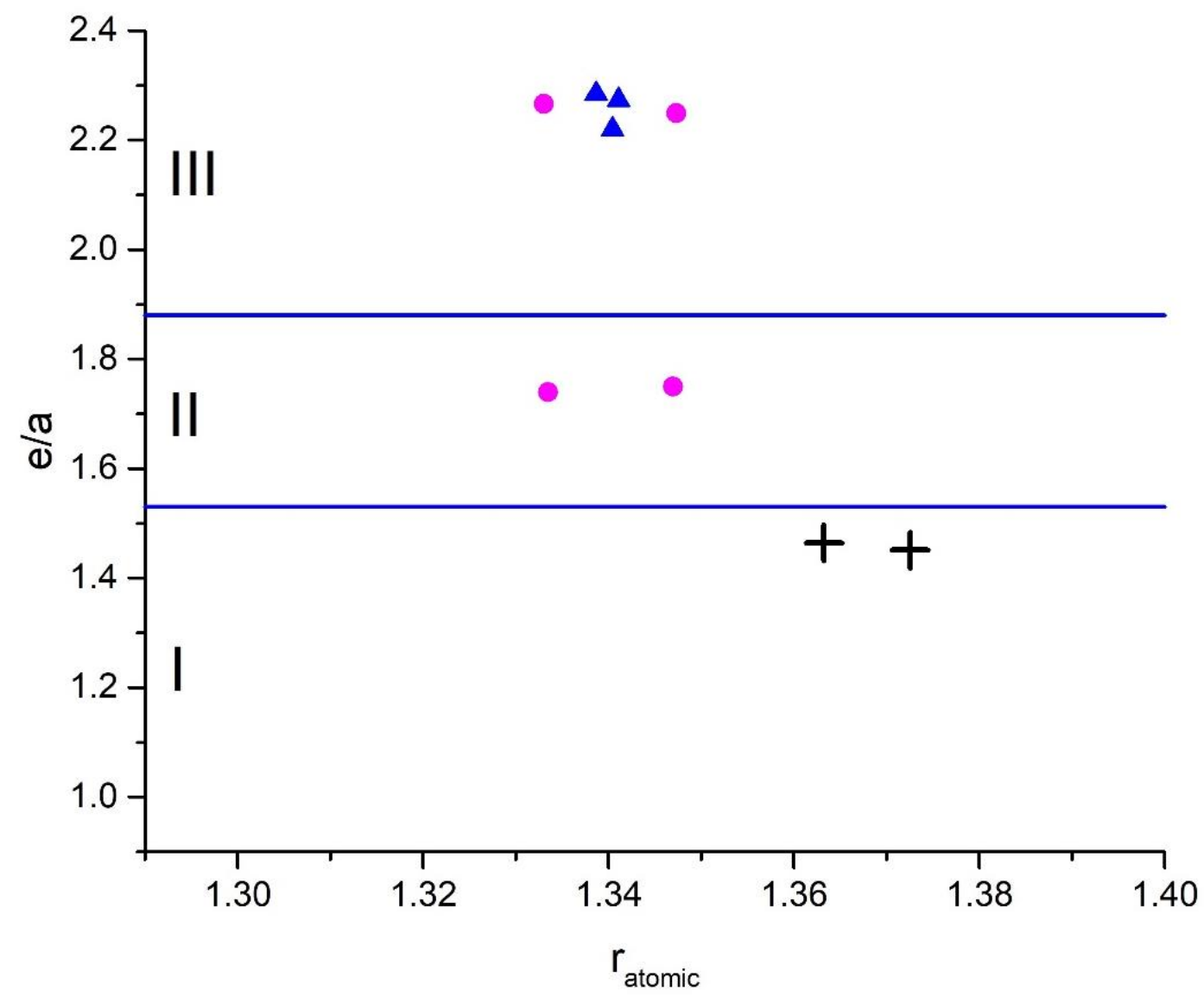

Fig. 8b: e/a as a function of atomic radius for the designed alloys. The symbols indicate the types of phases identified by diffraction: $+\mathrm{HV}<300,-300<\mathrm{HV}<450, \Delta \mathrm{HV}>450$. The horizontal bars define the domains I, II and III. 


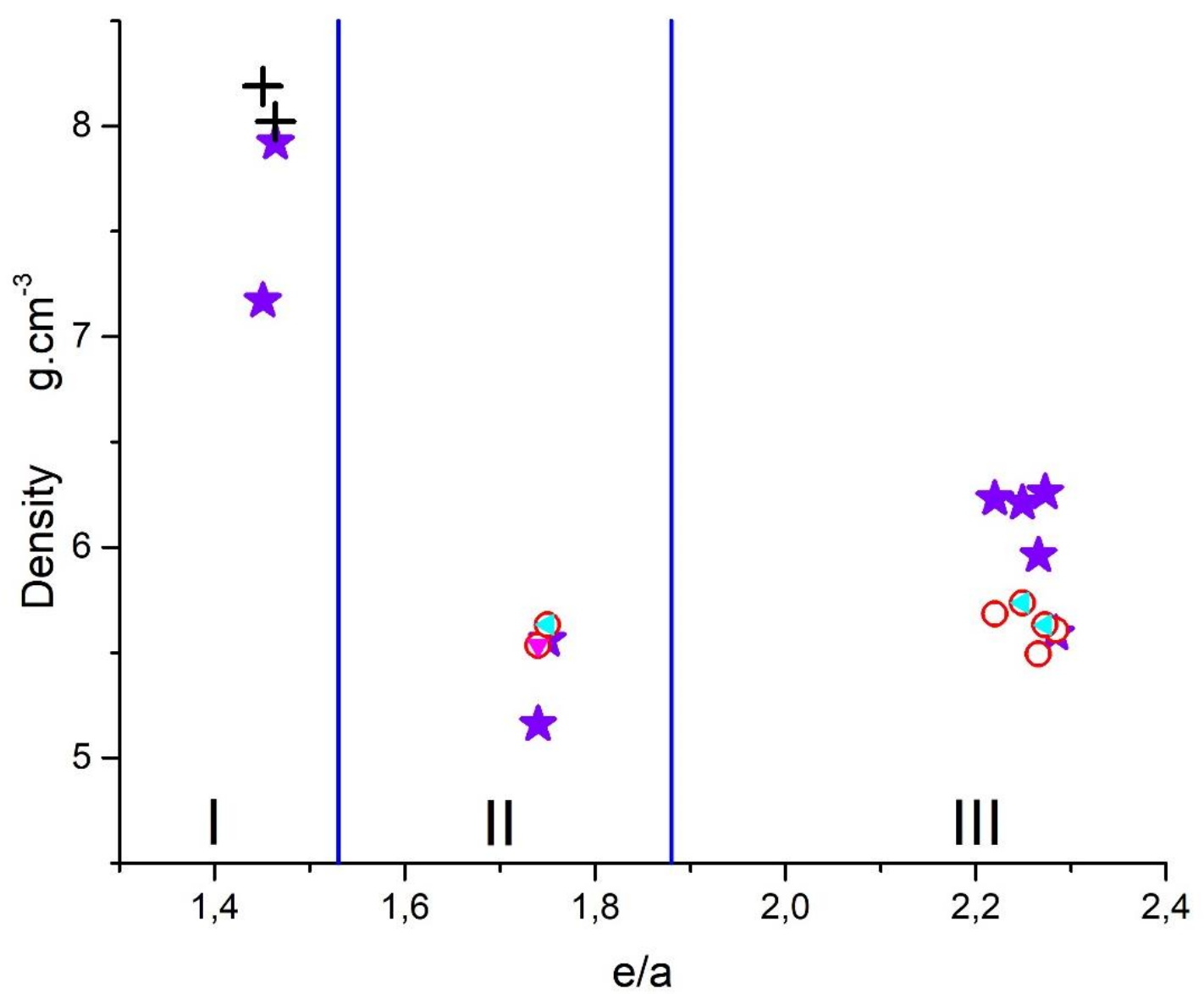

Fig. 8c: Calculated density as a function of e/a for the designed alloys. The symbols indicate the types of phases identified by diffraction: + fcc, $\circ$ bcc, $\nabla$ intermetallic or sigma phases no diffraction data available and $\star$ the density measured on the produced alloys. The vertical bars define the domains I, II and III.

Two types of alloys could be designed (Fig. 8a): in Domain I, alloys with fcc phases and in Domain III, alloys with bcc phases. In Domain II, the alloys have mixed phases.

In Fig. 8b, it can be seen that, as predicted, the fcc designed HEA alloys in Domain I have Vickers hardness below 300 and the bcc designed HEA alloys in Domain III have Vickers hardness higher than 300 .

Fig. 8c presents the calculated one from textbook data and atomic percentage of the elements as a function of e/a. For each designed HEA alloy, the symbol indicates the phases 
present. The star symbols indicate the measured density for each designed alloy. The expected densities of the designed alloys are very close to the measured ones.

Fig. 8, a to c give a good example of the strength of classification of High Entropy Alloys within the [e/a; atomic radius] framework to design alloys with specific elements and targeted hardness, phases and density.

The importance of the number of itinerant electrons per atom, e/a, in predicting the phases and properties in solid solutions was stressed as early as 1966 [78]. In [79] the use of e/a as opposed to an approach using the total number of valence electrons per atom (VEC) is discussed by Massalski for the determination of Hume-Rothery phases.

As detailed in [31] and [70], the application of this approach for HEAs is suitable because the approximation of solid solutions is applicable when the composition of each constituting element is within the limits defined by Yeh [1], i.e. superior to 5 at $\%$ and inferior to 35 at $\%$.

In the present study, the authors have shown that the atomic radius has to be associated to e/a in order to give a full classification and design.

Thus, because the e/a and atomic radius are easily available from any textbook, such an approach can quickly identify potential alloy compositions of interest within user-targeted domains.

Furthermore, from a modelling perspective this classification system can be easily implemented as a numerical model to provide very fast screening of a large number of potential compositions. The compositions identified by the numerical implementation of this classification system can be used as a basis for DoE for experimental combinatorial studies. 


\section{Conclusions}

The combined influence of e/a and the atomic radius clearly separate alloys with fcc, bcc and hcp types of structure.

The three e/a Domains as identified in [31,70] are still the following:

Domain I: fcc. e/a<1.53

Domain III: bcc type: e/a > 1.88

Domain II: mixed phases. Sigma, intermetallics.

The following Domain should be added for the occurrence of hcp phases:

$$
\begin{aligned}
& r<1.365 \text { in Domain I } \\
& r>1.387 \text { in Domain III. }
\end{aligned}
$$

By using this classification, it is possible to determine compositions of HEA alloys with adequate range of hardness, density and phases present.

The consequences of such predictions when modelling the structure and mechanical behaviour of HEAs is fundamental for their application.

\section{Acknowledgements}

The authors are thankful to Institute Laue-Langevin, Grenoble, France, for awarding beam-time on the D20 diffractometer at the ILL reactor. The present work has been carried out within the FP7 European project AccMet NMP4-LA-2011-263206 for support. The authors would also like to thank COMET at Swansea University for support. the Welsh Government, European Regional Development Fund (ERDF) and SMARTExpertise Wales for funding the Materials Advanced Characterisation Centre (MACH1) and Combinatorial Metallurgy (COMET) at Swansea University. 
The data that support the findings of this study are available from the corresponding author, [MCD], upon reasonable request. 


\section{References}

[1] J.W. Yeh, S.K. Chen, S.J. Lin, J.Y. Gan, T.S. Chin, T.T. Shun, C.H. Tsau, S.Y. Chang, Nanostructured high-entropy alloys with multiple principal elements: novel alloy design concepts and outcomes, Adv. Eng. Mater. 6 (2004) 299-303.

https://doi.org/10.1002/adem.200300567

[2] B. Cantor, I.T.H. Chang, P. Knight, A.J.B. Vincent, Microstructural development in equiatomic multicomponent alloys, Mater. Sci. Eng. A 375-377 (2004) 213-218. https://doi.org/10.1016/j.msea.2003.10.257.

[3] M.C. Gao, J.W. Yeh, P.K. Liaw, Y. Zhang Y. High-Entropy alloys: Fundamentals and applications, Springer, 2016. ISBN 978-3-319-27011-1.

[4] S. Guo, Q. Hu, C. Ng, C.T. Liu. More than entropy in high-entropy alloys: Forming solid solutions or amorphous phase. Intermetallics 41 ( 2013) 96-103.

https://doi.org/10.1016/j.intermet.2013.05.002

[5] D.B. Miracle, J.D. Miller, O.N. Senkov, C. Woodward, M.D. Uchic, J. Tiley, Exploration and Development of High Entropy Alloys for Structural Applications, Entropy 16 (2014) 494525. https://doi.org/10.3390/e16010494

[6] D.B. Miracle, O.N. Senkov, A critical review of high entropy alloys and related concepts, Acta Mater. 122 (2017) 448-511. https://doi.org/10.1016/j.actamat.2016.08.081

[7] O.N. Senkov, J.D. Miller, D.B. Miracle, C. Woodward, Accelerated exploration of multiprincipal element alloys with solid solution phases, Nature Comm. 6 (2015) 6529. https://doi.org/10.1038/ncomms7529

[8] M.H. Tsai, J.W. Yeh, High-entropy alloys: A critical review, Mater. Res. Lett. 2-3 (2014) 107-123. https://doi.org/10.1080/21663831.2014.912690

[9] Z.P Lu, H. Wang, M.W. Chen, I. Baker, J.W. Yeh, C.T. Liu, T.G. Nieh, An assessment on the future development of high-entropy alloys: Summary from a recent workshop, Intermetallics 66 (2015) 67-76. https://doi.org/10.1016/j.intermet.2015.06.021.

[10] Y. Zhang, T.T Zuo, Z. Tang, M.C Gao, K.A. Dahmen, P.K. Liaw, Z.P. Lu, Microstructures and properties of high-entropy alloys, Prog. Mater. Sci. 61 (2014) 1-93. https://doi.org/10.1016/j.pmatsci.2013.10.001

[11] R. Kozak, A.S. Sologubenko, W. Steurer, Single-phase high-entropy alloys - an overview. Zeitschrift fuer Kristallographie Crystalline Materials 230 (2015) 55-68. https://doi.org/10.1515/zkri-2014-1739

[12] W. Steurer, Single-phase high-entropy alloys-A critical update. Mater. Charact. 162 (2020) 110179. https://doi.org/10.1016/j.matchar.2020.110179.

[13] D.J.M. King, S.C. Middleburgh, A.G. McGregor, M.B. Cortie, Predicting the formation and stability of single phase high-entropy alloys. Acta Mater. 104 (2016) 172-179. https://doi.org/10.1016/j.actamat.2015.11.040 
[14] U. Dahlborg, J. Cornide, M. Calvo-Dahlborg, T. Hansen, A. Fitch, Z. Leong, S. Chambreland, R. Goodall, Structure of some $\mathrm{CoCrFeNi}$ and $\mathrm{CoCrFeNiPd} \mathrm{x}_{\mathrm{x}}$ multicomponent HEA alloys by diffraction techniques, J. Alloys Compds 681 (2016) 330-341. http://dx.doi.org/10.1016/j.jallcom.2016.04.248.

[15] M.G. Poletti, L. Battezzati, Electronic and thermodynamic criteria for the occurrence of high entropy alloys in metallic systems, Acta Mater. 75 (2014) 297-306. https://doi.org/10.1016/j.actamat.2014.04.033

[16] I. Toda-Caraballo, P.E.L. Rivera-Díaz-del-Castillo, A criterion for formation of high entropy alloys based on lattice distortion, Intermetallics 71 (2016) 76-87. https://doi.org/10.1016/j.intermet.2015.12.011

[17] Z.Y. Leong, Y.H. Huang, R. Goodall, I. Todd, Electronegativity and enthalpy of mixing biplots for High Entropy Alloy solid solution prediction, Mater. Chem. Phys. 210 (2018) 259268.https://doi.org/10.1016/j.matchemphys.2017.09.001

[18] S.A. Firstov, V.F. Gorban', N.A. Krapivka, M.V. Karpets, É.P. Pechkovskii, Effect of electron density on phase composition of high-entropy equiatomic alloys, Powder Metallurgy and Metal Ceramics 54 (2016) 607-613.

https://doi.org/10.1007/s11106-016-9754-7

[19] Y.P Wang, B.S. Li, H.Z. Fu, Solid solution or intermetallics in a high-entropy alloy, Adv. Eng. Mater. 11 (2009) 641-644. https://doi.org/10.1002/adem.200900057

[20] X. Yang, Y. Zhang, Prediction of high-entropy stabilized solid-solution in multicomponent alloys, Mater. Chem. and Phys. 132 (2012) 233-238.

https://doi.org/10.1016/j.matchemphys.2011.11.021

[21] M. Calvo-Dahlborg, U. Dahlborg, J. Cornide, S. Mehraban, Z. Leong, T.C. Hansen, R.K. Wunderlich, R. Goodall, N.P. Lavery, S.G.R. Brown, Structural investigation of the stability in temperature of some high entropy / multi major components alloys as a function of their electronic structure. J. Alloys and Compds 837 (2020) 155496.

https://doi.org/10.1016/i.jallcom.2020.15549

[22] C.D. Gómez-Esparza, J. Camarillo-Cisneros, I. Estrada-Guel, J.G. Cabañas Moreno, J.M. Herrera-Ramírez, R. Martínez-Sánchez. Effect of $\mathrm{Cr}$, Mo and Ti on the microstructure and Vickers hardness of multicomponent systems, Mech. Astron. 51 (2008) 427-437. https://doi.org/10.1016/j.jallcom.2014.01.081

[23] Y.F. Kao, T.J. Chen, S.K. Chen, J.W. Yeh, Microstructure and mechanical property of ascast, -homogenized, and -deformed $\mathrm{Al}_{\mathrm{x}} \mathrm{CoCrFeNi}(0 \leq \mathrm{x} \leq 2)$ high-entropy alloys, J. Alloys Compds 488 (2009) 57-64. http://doi:10.1016/j.jallcom.2009.08.090

[24] Z.Z. Li, S.T. Zhao, R. O. Ritchie, M.A. Meyers, Mechanical properties of high-entropy alloys with emphasis on face-centered cubic alloys, Progr. Mater. Sci. 102 (2019) 296-345. https://doi.org/10.1016/j.pmatsci.2018.12.003. 
[25] Z.P Lu, Z.F Lei, H.L. Huang, S.F. Liu, F. Zhang, D.B. Duan, P.P. Cao, Y. Wu, X. Liu, H. Wang, Deformation behavior and toughening of High-Entropy Alloys, Acta Metall Sin. 54 (2018) 1553-1566. https://doi.org/10.11900/0412.1961.2018.00372

[26] R. Razuan, N.A. Jani, M.K. Harun, M.K. Talari, Microstructure and hardness properties investigation of $\mathrm{Ti}$ and $\mathrm{Nb}$ added $\mathrm{FeNiAlCuCrTi} \mathrm{Nb}_{\mathrm{y}}$ High Entropy Alloys, Trans. Indian Inst. Met. 66 (2013) 309-312. https://doi.org/10.1007/s12666-013-0265-7

[27] T.T. Shun, W.J. Hung, Effects of Cr content on microstructure and mechanical properties of $\mathrm{AlCoCr}_{\mathrm{x}} \mathrm{FeNi}$ High-Entropy Alloy. Hindawi Adv. Mater. Sci. Eng. (2018) 5826467. https://doi.org/10.1155/2018/5826467.

[28] C.J. Tong, M.R. Chen, S.K. Chen, J.W. Yeh, T.T. Shun, S.J. Lin, S.Y. Chang, Mechanical performance of the $\mathrm{Al}_{\mathrm{x}} \mathrm{CoCrCuFeNi}$ High-Entropy Alloy system with multiprincipal elements, Metall. Mater. Trans. A 36 (2005) 1263.

https://doi.org/10.1007/s11661-005-0218-9

[29] S.A. Uporov, R.E. Ryltsev, V.A. Bykov, S. Kh Estemirova, D.A. Zamyatin, Microstructure, phase formation and physical properties of AlCoCrFeNiMn high-entropy alloy, J. Alloys Compds 820 (2020) 153228.

https://doi.org/10.1016/j.jallcom.2019.153228.

[30] J. Xu, J.Y. Zhang, Y.Q. Wang, P. Zhang, J. Kuang, G. Liu, G.J. Zhang, J. Sun. Annealingdependent microstructure, magnetic and mechanical properties of high-entropy $\mathrm{FeCoNiAl}_{0.5}$ alloy. Mater. Sci. Eng. A 776 (2020) 139003.

https://doi.org/10.1016/j.msea.2020.139003.

[31] M. Calvo-Dahlborg, S.G.R. Brown, Hume-Rothery for HEA classification and selforganizing map for phases and properties prediction, J. Alloys Compds 724 (2017) 353-364. http://dx.doi.org/10.1016/j.jallcom.2017.07.074

[32] C. Li, J.C. Li, M. Zhao, Q. Jiang, Effect of alloying elements on microstructure and properties of multiprincipal elements high-entropy alloys, J. Alloys Compds 475 (2009) 752 757.https://doi.org/10.1016/j.jallcom.2008.07.124

[33] Y.S. Lee, R.J. Cava, Superconductivity in high and medium entropy alloys based on MoReRu, Physica C: Superconductivity and its Applications 566, (2019) 1353520. https://doi.org/10.1016/j.physc.2019.1353520

[34] A. Takeuchi, T. Wada, H. Kato, High-Entropy Alloys with Hexagonal Close-Packed structure in $\operatorname{Ir}_{26} \mathrm{Mo}_{20} \mathrm{Rh}_{22.5} \mathrm{Ru}_{20} \mathrm{~W}_{11.5}$ and $\operatorname{Ir}_{25.5} \mathrm{Mo}_{20} \mathrm{Rh}_{20} \mathrm{Ru}_{25} \mathrm{~W}_{9.5}$ alloys designed by sandwich strategy for the Valence Electron Concentration of constituent elements in the periodic chart, Mater. Trans. 60 (2019) 1666-1673.

https://doi.org/10.2320/matertrans.M2019037

[35] C.M. Lin, H.L. Tsai, H.Y. Bor, Effect of aging treatment on microstructure and properties of high-entropy $\mathrm{Cu}_{0.5} \mathrm{CoCrFeNi}$ alloy. Intermetallics 18 (2010) 1244-1250.

https://doi.org/10.1016/j.intermet.2010.03.030

[36] X.F. Wang, Y. Zhang, Y. Qiao, G.L. Chen. Novel microstructure and properties of multicomponent CoCrCuFeNiTi ${ }_{x}$ alloys. Intermetallics 15 (2007) 357-362. 
https://doi.org/10.1016/j.intermet.2006.08.005

[37] J.W. Yeh, Recent progress in high-entropy alloys, Annales de Chimie-Science des Materiaux 31(2006) 633-648. https://doi.org/10.3166/ACSM.31.633-648

[38] L. Liu, J.B. Zhu, C. Zhang, J.C .Li, Q. Jiang, Microstructure and the properties of FeCoCuNiSn ${ }_{x}$ high entropy alloys, Mat. Sci. Eng. A 548 (2012) 64-68.

https://doi.org/10.1016/j.msea.2012.03.080.

[39] S. Riva, S. Mehraban, N.P. Lavery, S. Schwarzmüller, O. Oeckler, S.G.R. Brown, K.V. Yusenko, The effect of Scandium ternary intergrain precipitates in Al-containing High-Entropy Alloys, Entropy 20 (2018) 488. https://doi.org/10.3390/e20070488

[40] M.R. Chen, S.J. Lin, J.W. Yeh, M.H. Chuang, S.K. Chen, Y.S. Huang, Effect of vanadium addition on the microstructure, hardness, and wear resistance of $\mathrm{Al}_{0.5} \mathrm{CoCrCuFeNi}$ high-entropy alloy, Met. Mat. Trans. A 37 (2006) 1363-1369. https://doi.org/10.1007/s11661-006-0081-3.

[41] M.H. Chuang, M.H.Tsai, W.R. Wang, S.J. Lin, J.W. Yeh, Microstructure and wear behavior of $\mathrm{Al}_{\mathrm{x}} \mathrm{Co}_{1.5} \mathrm{CrFeNi}_{1.5}$ Tiy high-entropy alloys. Acta Mater. 59 (2011) 6308-6317. https://doi.org/10.1016/j.actamat.2011.06.041.

[42] C.P. Lee, Y.Y. Chen, C.Y. Hsu, J.W. Yeh, H.C. Shih, The effect of Boron on the corrosion resistance of the High Entropy Alloys $\mathrm{Al}_{0.5} \mathrm{CoCrCuFeNiB}_{\mathrm{x}}$, J. Electrochem. Soc. 154 (2007) 8 C424. https://doi.org/10.1149/1.2744133.

[43] O.N. Senkov, G.B. Wilks, J.M. Scott, D.B. Miracle, Mechanical properties of $\mathrm{Nb}_{25} \mathrm{Mo}_{25} \mathrm{Ta}_{25} \mathrm{~W}_{25}$ and $\mathrm{V}_{20} \mathrm{Nb}_{20} \mathrm{Mo}_{20} \mathrm{Ta}_{20} \mathrm{~W}_{20}$ refractory high entropy alloys, Intermetallics 19 (2011) 698-706. https://doi.org/10.1016/j.intermet.2011.01.004.

[44] K.B. Zhang, Z.Y. Fu, J.Y. Zhang, W.M. Wang, H. Wang, Y.C. Wang, Q.J. Zhang, J. Shi, Microstructure and mechanical properties of $\mathrm{CoCrFeNiTiAl}_{\mathrm{x}}$ high-entropy alloys, Mat. Sci. Eng. A 508 (2009) 214-219. https://doi.org/10.1016/j.msea.2008.12.053.

[45] W.P. Chen, Z.Q. Fu, S.C. Fang, H.Q. Xiao, D.Z. Zhu, Alloying behavior, microstructure and mechanical properties in a $\mathrm{FeNiCrCo}_{0.3} \mathrm{Al}_{0.7}$ high entropy alloy, Materials \& Design 51 (2013) 854-860. https://doi.org/10.1016/j.matdes.2013.04.061.

[46] Z.H. Hu, Y.Z. Zhan, G.H. Zhang, J. She, C.H. Li, Effect of rare earth Y addition on the microstructure and mechanical properties of high entropy AlCoCrCuNiTi alloys. Materials \& Design, 31 (2010) 1599-1602. https://doi.org/10.1016/j.matdes.2009.09.016.

[47] S.G. Ma, Y. Zhang, Effect of $\mathrm{Nb}$ addition on the microstructure and properties of AlCoCrFeNi high-entropy alloy, Mat. Sci. Eng. A 532 (2012) 480-486.

https://doi.org/10.1016/j.msea.2011.10.110.

[48] C.Y. Hsu, W.R. Wang, W.Y. Tang, S.K. Chen, J.W. Yeh, Microstructure and mechanical properties of new $\mathrm{AlCo}_{\mathrm{x}} \mathrm{CrFeMo}_{0.5} \mathrm{Ni}$ High-Entropy Alloys, Adv. Eng. Mat. 12 (2010) 44-49. https://doi.org/10.1002/adem.200900171. 
[49] C.Y. Hsu, T.S. Sheu, J.W. Yeh, S.K. Chen, Effect of iron content on wear behavior of $\mathrm{AlCoCrFe}_{\mathrm{x}} \mathrm{Mo}_{0.5} \mathrm{Ni}$ high-entropy alloys, Wear 268 (2010) 653-659. https://doi.org/10.1016/j.wear.2009.10.013.

[50] J.Y. He, W.H. Liu, H. Wang, Y. Wu, X.J. Liu, T.G. Nieh, Z.P .Lu, Effects of Al addition on structural evolution and tensile properties of the FeCoNiCrMn high-entropy alloy system, Acta Mater. 62 (2014) 105-113. https://doi.org/10.1016/j.actamat.2013.09.037.

[51] B.S. Li, Y.P. Wang, M.X. Ren, C. Yang, H.Z. Fu, Effects of Mn, Ti and V on the microstructure and properties of $\mathrm{AlCrFeCoNiCu}$ high entropy alloy, Mater. Sci. Eng. A 498 (2008) 482-486. https://doi.org/10.1016/j.msea.2008.08.025.

[52] S.T. Chen, W.Y. Tang, Y.F. Kuo, S.Y. Chen, C.H. Tsau, T.T. Shun, J.W. Yeh, Microstructure and properties of age-hardenable $\mathrm{Al}_{\mathrm{x}} \mathrm{CrFe}_{1.5} \mathrm{MnNi}_{0.5}$ alloys, Mater. Sci. Eng. A 527 (2010) 5818-5825. https://doi.org/10.1016/j.msea.2010.05.052.

[53] J.M. Zhu, H.M. Fu, H.F. Zhang, A.M. Wang, H. Li, Z.Q. Hu, Microstructures and compressive properties of multicomponent $\mathrm{AlCoCrFeNiMox}$ alloys. Mater. Sci. Eng. A 527 (2010) 6975-6979. https://doi.org/10.1016/j.msea.2010.07.028.

[54] Y. Dong, Y.P. Lu, J.R. Kong, J.J. Zhang, T.J. Li, Microstructure and mechanical properties of multi-component AlCrFeNiMo high-entropy alloys, J. Alloys Compds 573 (2013) 96-101. https://doi.org/10.1016/j.jallcom.2013.03.253.

[55] C.D. Gómez-Esparza, J. Camarillo-Cisneros, I. Estrada-Guel, J.G. Cabañas-Moreno, J.M. Herrera-Ramírez, R. Martínez-Sánchez, Effect of Cr, Mo and Ti on the microstructure and Vickers hardness of multi-component systems, J. Alloys Compds 615, Supp. 1 (2014) S638S644. https://doi.org/10.1016/j.jallcom.2014.01.081.

[56] É. Fazakas, V. Zadorozhnyy, L.K. Varga, A. Inoue, D.V. Louzguine-Luzgin, F.Y. Tian, L. Vitos, Experimental and theoretical study of $\mathrm{Ti}_{20} \mathrm{Zr}_{20} \mathrm{Hf}_{20} \mathrm{Nb}_{20} \mathrm{X}_{20}(\mathrm{X}=\mathrm{V}$ or $\mathrm{Cr})$ refractory highentropy alloys, Int. J. Refractory Metals and Hard Materials 47 (2014) 131-138. https://doi.org/10.1016/j.ijrmhm.2014.07.009.

[57] Y.X. Zhuang, W.J. Liu, Z.Y. Chen, H.D. Xue, J.C. He, Effect of elemental interaction on microstructure and mechanical properties of $\mathrm{FeCoNiCuAl}$ alloys. Mater. Sci. Eng. A 556 (2012) 395-399. https://doi.org/10.1016/j.msea.2012.07.003.

[58] Y.J. Zhou, Y. Zhang, Y.L. Wang, G.L. Chen, Solid solution alloys of AlCoCrFeNiTix AlCoCrFeNiTi $i_{x}$ with excellent room-temperature mechanical properties, Appl. Phys. Lett. 90 (2007) 181904. https://doi.org/10.1063/1.2734517.

[59] J.M. Zhu, H.M. Fu, H.F. Zhang, A.M. Wang, H. Li, Z.Q. Hu, Synthesis and properties of multiprincipal component AlCoCrFeNiSix alloys, Mater. Sci. Eng. A 527 (2010) 7210-7214. https://doi.org/10.1016/j.msea.2010.07.049.

[60] C.Y. Hsu, CC. Juan, T.S. Sheu, S.K. Chen, J.W. Yeh, Effect of Aluminum content on microstructure and mechanical properties of $\mathrm{Al}_{\mathrm{x}} \mathrm{CoCrFeMo} \mathrm{o}_{0.5} \mathrm{Ni}$ High-Entropy Alloys, J. Minerals, Met. Mater. Soc. (TMS) 65 (2013) 1840-1847.

https://doi.org/10.1007/s11837-013-0753-6. 
[61] J.W. Qiao, M.L. Bao, Y.J. Zhao, H.J. Yang, Y.C. Wu, Y. Zhang, J.A. Hawk, M.C. Gao, Rare-earth high entropy alloys with hexagonal close-packed structure, J. App. Phys. 124 (2018) 195101. https://doi.org/10.1063/1.5051514.

[62] M. Feuerbacher, M. Heidelmann, C. Thomas, Hexagonal High-entropy Alloys, Mater. Res. Lett. 3 (2015) 1-6.

http://dx.doi.org/10.1080/21663831.2014.951493.

[63] N.D. Stepanov D.G. Shaysultanov, G.A. Salishchev, M.A. Tikhonovsky, Structure and mechanical properties of a light-weight AlNbTiV high entropy alloy, Mater. Lett. 142 (2015) 153-155. https://doi.org/10.1016/j.matlet.2014.11.162.

[64] A. Takeuchi, K. Amiya, T. Wada, K. Yubuta, W. Zhang, High-Entropy Alloys with a Hexagonal Close-Packed structure designed by equi-atomic alloy strategy and binary phase diagrams, JOM J. Minerals, Met. Mater. Soc. 66 (2014) 1984-1992. https://doi.org/10.1007/s11837-014-1085-X

[65] S. Uporov, S.Kh. Estemirova, V.A. Bykov, D.A. Zamyatin, R.E. Ryltsev. A single-phase ScTiZrHf high-entropy alloy with thermally stable hexagonal close-packed structure, Intermetallics 122 (2020) 106802. https://doi.org/10.1016/

[66] X. Yang, Y. Zhang, P.K. Liaw, Microstructure and compressive properties of $\mathrm{NbTiVTaAl}_{\mathrm{x}}$ High Entropy Alloys, Procedia Engineering $36 \quad$ (2012) 292-298. https://doi.org/10.1016/j.proeng.2012.03.043.

[67] Y. Yuan, Y. Wu, X. Tong, H. Zhang, H. Wang, X.J. Liu, L. Ma, H.L. Suo, Z.P. Lu, Rareearth high-entropy alloys with giant magnetocaloric effect, Acta Mater. 125 (2017) 481-489. https://doi.org/10.1016/j.actamat.2016.12.021.

[68] Y.J. Zhao, J.W. Qiao, S.G. Mac, M.C. Gao, H.J. Yang, M.W. Chen, Y. Zhang, A hexagonal close-packed high-entropy alloy: The effect of entropy, Materials \& Design 96 (2016) 10-15. https://doi.org/10.1016/j.matdes.2016.01.149.

[69] T.T. Zuo, R.B. Li, X.J. Ren, Y. Zhang, Effects of Al and Si addition on the structure and properties of CoFeNi equal atomic ratio alloy, J. Mag. Mag. Mater. 371 (2014) 60-68. https://doi.org/10.1016/j.jmmm.2014.07.023.

[70] M. Calvo-Dahlborg, U. Dahlborg, S. G. Brown, J. Juraszek, Influence of the electronic polymorphism of $\mathrm{Ni}$ on the classification and design of high entropy alloys, J. Alloys Compds 824 (2020) 153895. https://doi.org/10.1016/j.jallcom.2020.153895

[71] J. Cieslak, J. Tobola, J. Przewoznik, K. Berent, U. Dahlborg, J. Cornide, S. Mehraban, N. Lavery, M. Calvo-Dahlborg, Multi-phase nature of sintered vs. arc-melted $\mathrm{Cr}_{\mathrm{x}} \mathrm{AlFeCoNi}$ high entropy alloys - experimental and theoretical study. J. Alloys Compds 801 (2019) 511-519. https://doi.org/10.1016/j.jallcom.2019.06.121

[72] M. Calvo-Dahlborg, J. Cornide, U. Dahlborg, S. Chambreland, G.D. Hatton, A. Fones, Structure and microstructural characterization of CoCrFeNiPd High Entropy Alloys. Solid State Phenomena 257 (2016) 72-75. https://www.scientific.net/SSP.257.72 
[73] U. Dahlborg, J. Cornide, M. Calvo-Dahlborg, T.C. Hansen, Z. Leong, L. Asensio Dominguez, S. Chambreland, A. Cunliffe, R. Goodall, I. Todd, Crystalline structures of some High Entropy Alloys obtained by Neutron and X-ray diffraction, Acta. Phys. Polonica A 128 (2015) 552. http://dx.doi.org/10.12693/APhysPolA.128.552

[74] J. Cornide, U. Dahlborg, Z. Leong, L. Asensio Dominguez, J. Juraszek, S. Jouen, T. Hansen, R. Wunderlich, S. Chambreland, I. Todd, R. Goodall, M. Calvo-Dahlborg, Structure and properties of some CoCrFeNi-based high Entropy alloys, TMS2015 (The Minerals, Metals \& Materials Society), Orlando (USA) 2015. http://dx.doi.org/10.1002/9781119093466.ch139

[75] J. Cornide, M. Calvo-Dahlborg, S. Chambreland, L. Asensio Dominguez, Z. Leong, A. Cunliffe, R. Goodall, I. Todd, Combined Atom Probe Tomography and TEM investigations of $\mathrm{CoCrFeNi}, \mathrm{CoCrFeNi}-\mathrm{Pd}_{\mathrm{x}}(\mathrm{x}=0.5,1.0,1.5)$ and $\mathrm{CoCrFeNi}-\mathrm{Sn}$. Acta Physica Polonica A 128 (2015) 557-560. http://doi.org/10.12693/APhysPolA.128.557

[76] U. Dahlborg, M. Calvo-Dahlborg, J. Cornide, R. Goodall, T. Hansen, Z. Leong, E. Suard, I. Todd, Structure of high entropy alloys, Institut Laue-Langevin (ILL) (2014) https://doi.ill.fr/10.5291/ILL-DATA.1-01-140

[77] A. Boultif, D. Louër, Powder pattern indexing with the dichotomy method, J. Appl. Cryst. 37 (2004) 724-731.https://doi.org/10.1107/S0021889804014876

[78] C.S. Barrett, T.B. Massalski, Structure of metals, third edition. McGraw-Hill Eds. 1966. P. 306-379.

[79] T.B. Massalski, Comments Concerning Some Features of Phase Diagrams and Phase Transformations, Materials Transactions 51 (2010) 583-596.

https://doi.org/10.2320/materia.49.192.

[80] E.T. Teatum, K.A. Gschneidner Jr., J.T. Waber, 1968. Report LA-4003. UC-25. Metals, Ceramics and Materials. TID-4500, Los Alamos Scientific Laboratory.

[81] W. Hume-Rothery, G.W. Mabbot, K.M. Channel Evans, The freezing points, melting points and solid solubility limits of the alloys of silver and copper with the elements of the Bsub-groups, Phil. Trans. Royal Soc. London A 232 (1934) 1-97.

[82] W. Hume-Rothery, Atomic diameters, atomic volumes, and solid solubility relations in alloys, Acta Metallurgica 14 (1966) 17-20. 


\section{Figure captions}

Fig. 1: Vickers hardness, as a function of e/a for the investigated alloys in as cast conditions. The symbols indicate the types of phases identified by diffraction: + fcc, $\circ$ bcc, $\diamond$ hcp, $\triangle \mathrm{B} 2$, $\square$ fcc + bcc, $\times$ L21, $\triangle$ no diffraction data available. The vertical bars define the domains I, II and III.

Fig. 2: Vickers hardness, as a function of the average calculated Teatum [80] radius for the investigated alloys in as cast conditions. The symbols indicate the types of phases identified by diffraction: + fcc, $\circ$ bcc, $\diamond$ hcp, $\triangle \mathrm{B} 2, \square$ fcc+bcc, $\times$ L21, $>$ no diffraction data available.

Fig. 3: e/a, as a function of $\mathbf{r}_{\text {Teatum }}$ for the investigated alloys in as cast conditions. The symbols indicate the types of phases identified by diffraction: + fcc, $\circ$ bcc, $\diamond$ hcp, $\triangle \mathrm{B} 2, \square$ fcc+bcc, $\times$ L $21, \nabla$ intermetallic or sigma phases, $*$ mixed phases, $<$ no diffraction data available. The horizontal bars define the domains I, II and III.

Fig. 4: e/a, as a function of atomic radius, $\mathrm{r}_{\text {Atomic }}$, for the investigated alloys in as cast conditions. The symbols indicate the types of phases identified by diffraction: + fcc, $\circ$ bcc, $\bullet$ hcp, $\triangle \mathrm{B} 2$, $\square$ fcc+bcc, $\times$ L21, $\nabla$ intermetallic or sigma phases, $*$ mixed phases, $\varangle$ no diffraction data available. The horizontal bars define the domains I, II and III. The vertical bars determine radius domains

Fig. 5: e/a, as a function of atomic radius, $\mathrm{r}_{\text {Atomic }}$, for as cast bibliography alloys. The symbols indicate the types of phases identified by diffraction: + fcc, $\circ$ bcc, $\diamond$ hcp, $\triangle \mathrm{B} 2, \square$ fcc+bcc, $\times$ L $21, \nabla$ intermetallic or sigma phases, $*$ mixed phases, $\varangle$ no diffraction data available. The 
horizontal bars define the domains I, II and III and the vertical bars the identified radius domains. a) The whole range of radius. b) A zoom to easy comparison with Fig. 4.

Fig. 6: e/a, as a function of atomic radius, $\mathrm{r}_{\text {Atomic, }}$ a) for the investigated alloys in as cast conditions, b) for as cast bibliography alloys. The symbols indicate the types of phases identified by diffraction: $+\mathrm{HV}<300,-300<\mathrm{HV}<450, \Delta \quad 450<\mathrm{HV}<700$, * $\mathrm{HV}>700$. The horizontal bars define the domains I, II and III and the vertical bars the radius domains identified in Fig. 4.

Fig. 7: Calculated density, as a function of e/a for the investigated alloys in as cast conditions. The symbols indicate the types of phases identified by diffraction: + fcc, $\circ$ bcc, $\bullet$ hcp, $\triangle \mathrm{B} 2$, $\square$ fcc+bcc, $\times$ L21,,$\nabla$ intermetallic or sigma phases, $*$ mixed phases, $\langle$ no diffraction data available. The vertical bars define the domains I, II and III.

Fig. 8a: e/a as a function of atomic radius for the designed alloys. The symbols indicate the types of phases identified by diffraction: + fcc, $\circ$ bcc, $\nabla$ intermetallic or sigma phases $\langle$ no diffraction available. The horizontal bars define the domains I, II and III.

Fig. 8b: e/a as a function of atomic radius for the designed alloys. The symbols indicate the types of phases identified by diffraction: $+\mathrm{HV}<300,-300<\mathrm{HV}<450, \Delta \mathrm{HV}>450$. The horizontal bars define the domains I, II and III.

Fig. 8c: Calculated density as a function of e/a for the designed alloys. The symbols indicate the types of phases identified by diffraction: $+\mathrm{fcc}, \circ \mathrm{bcc}, \nabla$ intermetallic or sigma phases no diffraction data available and $\star$ the density measured on the produced alloys. The vertical bars define the domains I, II and III. 
